\title{
Natural Convection Heat Transfer of Copper- Water Nanofluid in an Inclined Square Cavity with Time-Periodic Boundary Conditions
}

\author{
Xi Meng \\ College of Architecture and Environment \\ Sichuan University \\ Chengdu, China \\ e-mail: mengxihvac@163.com \\ Yanna Gao \\ Faculty of Environmental Engineering \\ the University of Kitakyushu \\ Kitakyushu, Japan \\ e-mail: mengxihvac@163.com
}

\author{
Yanru Li \\ College of Architecture and Environment \\ Sichuan University \\ Chengdu, China \\ e-mail: lyricsyanru@gmail.com \\ Enshen Long* \\ College of Architecture and Environment \\ Sichuan University \\ Chengdu, China \\ e-mail: Longes2@163.com
}

\begin{abstract}
The paper presents a numerical study of natural convective heat transfer of copper-water in an inclined square cavity where the temperature of one sidewall sinusoidal oscillates, the opposite sidewall is cooled at a relatively low temperature and the other walls keep adiabatic. The transport equations are solved numerically with the finite volume approach using SIMPLEC algorithm. The influence of pertinent parameters such as the inclined angle $\left(-75^{\circ} \sim 75^{\circ}\right)$, the solid volume fraction of copper nanoparticles $(0 \sim 0.2)$ and the Rayleigh number $(104 \sim 106)$ on the convective heat transfer characters are studies. The results show that the heat transfer rate increases with the increase of the solid volume fraction and the Rayleigh number. And the percentage increase in the time-averaged Nusselt number is $\mathbf{3 7 . 6 1 \%}$, when the solid volume fraction is increased from $\phi=0$ to $\phi=0.2$ at $\mathrm{Ra}=106$. The positive inclined angle is more conducive to heat transfer enhancement than the negative inclined angle, especially for the higher Ra number. And there is the best inclined angle for a given $\mathrm{Ra}$ number, and this angle is $15^{\circ}$ at the $\mathrm{Ra}=106$.
\end{abstract}

Keywords-Nanofluids; natural convection; numerical simulation; volume fraction; thermal time-periodic boundary conditions

\section{INTRODUCTION}

Natural convective heat transfer is a universal and important phenomenon in the various thermal engineering. However, some traditional fluids such as water and oils are often used as heat transfer mediums in the some heat systems, but their low thermal conductivity is a primary limitation in enhancing the performance and the compactness of such systems. To overcome this drawback, an innovative way to enhance heat transfer is by using nanoparticles in the base fluid. The resulting mixture of the base fluid and nanoparticles, referred to as nanofluids, has a substantially larger thermal conductivity than that of traditional fluids. Some studies on nanofluids include thermal conductivity, forced convection heat transfer, boiling heat transfer, and natural convection heat transfer. Detailed review studies on nanofluids were reported by Murshed et al. [1], Yu et al. [2] and Kakac \& Pramuanjaroenkij [3]. And Saidur et al [4] and Huminic \& Huminic [5] summarized applications of nanofluids in the heat exchangers and heat pipes.

Above researches show nanofluids can substantially increase the heat transfer rate and improve heat exchange efficiency of some heat system [6], but their reaseach are more focused on the steady natural convection and there is little research on the dynamic natural convection of nanofluids. However, unsteady natural convection with time-dependent thermal conditions is more frequently encountered in bioengineering, chemical engineering, solar energy field etc. For example, the electrical components are frequently energized intermittently and generate heat in an unsteady manner [7]. The heat transfer process and influencing factors of unsteady natural convection are more complex than those of steady natural convection. To the best knowledge of the authors, Ghasemi and Aminossadati [8] were the first to investigate the periodic natural convection in a nanofluid-filled enclosure with oscillating heat flux. They found that the utilization of nanoparticles enhances the heat transfer rate especially at low Rayleigh numbers. Meanwhile, studies of natural convection in nanofluid-filled enclosures subject to timedependent temperature boundary conditions have not been reported in the literature. The main aim of present study is to investigate this problem and analyze the effects of the Rayleigh number, the solid volume fraction of nanoparticles and the inclined angle on flow and heat transfer.

\section{PHYSICAL MODEL AND GOVERNING FORMULATION}

As shown in Fig .1, a two-dimensional inclined cavity of side length $L$ filled with nanofluids is considered, where the temperature of left vertical sidewall is sinusoidal 
alternated with a constant average temperature, $T_{\text {avg, }}$ the right sidewall is cooled at a relatively low constant temperature $T_{\mathrm{C}}\left(T_{\mathrm{avg}} \geq T_{\mathrm{C}}\right)$, and the other walls are kept adiabatic. Fig .1(a) and (b) show the square cavities with positive and negative inclined angels respectively.

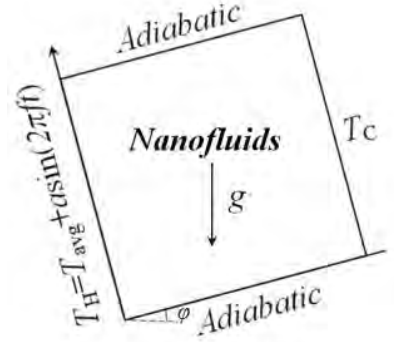

(a) $\varphi>0^{\circ}$

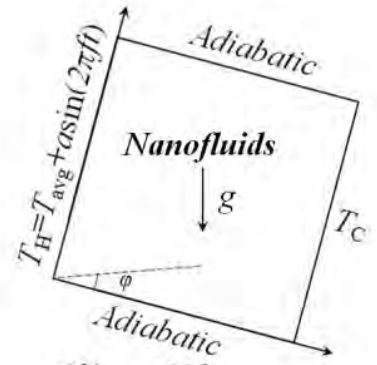

(b) $\varphi<0^{\circ}$
Figure 1. A schematic diagram of the physical model.

Only when the value of inclined angle $\varphi$ is less than $85^{\circ}$, natural convection can be thought as the twodimensional problem. So the various range of $\varphi$ is from $75^{\circ}$ to $75^{\circ}$ in our research. The fluid in the cavity is waterbase nanofluids $(\mathrm{Pr}=6.2)$ containing $\mathrm{Cu}$ nanoparticles. The nanofluids are assumed to be Newtonian fluid and incompressible, and the flow is laminar. It is assumed that the base fluid and the nanoparticles are in thermal equilibrium and no slip occurs between them. The thermophysical properties of the base fluid (pure water) and solid phase $(\mathrm{Cu})$ are given in Table I. Constant thermophysical properties are considered for the nanofluids except for the density variation in the buoyancy forces determined by using the Boussinesq approximation.

TABLE I. THERMOPHYSICAL PROPERTIES OF WATER AND NANOPARTICLES

\begin{tabular}{|l|l|l|}
\hline Physical properties & Water & Cu nanoparticles \\
\hline$\rho\left[\mathrm{kg} / \mathrm{m}^{3}\right]$ & 997.1 & 8933 \\
\hline$C_{\mathrm{P}}[\mathrm{J} /(\mathrm{kg} \cdot \mathrm{K})]$ & 4179 & 385 \\
\hline$k[\mathrm{~W} /(\mathrm{m} \cdot \mathrm{K})]$ & 0.613 & 401 \\
\hline$\alpha \times 10^{7}\left[\mathrm{~m}^{2} / \mathrm{s}\right]$ & 1.47 & 1165.97 \\
\hline$\beta \times 10^{6}[1 / \mathrm{K}]$ & 210 & 1.67 \\
\hline
\end{tabular}

With the foregoing mentioned assumptions, the continuity, momentum and energy equations for the laminar and unsteady state natural convection in the twodimensional cavity filled with the nanofluids can be written in the dimensional forms as follows:

$$
\begin{gathered}
\frac{\partial U}{\partial X}+\frac{\partial V}{\partial Y}=0 \\
\frac{\partial U}{\partial \tau}+U \frac{\partial U}{\partial X}+V \frac{\partial U}{\partial Y}=-\frac{\partial P}{\partial X}+\frac{\mu_{\mathrm{nf}}}{\rho_{\mathrm{nf}} \alpha_{\mathrm{f}}}\left(\frac{\partial^{2} U}{\partial X^{2}}+\frac{\partial^{2} U}{\partial Y^{2}}\right)+\frac{(\rho \beta)_{\mathrm{nf}}}{\rho_{\mathrm{nf}} \beta_{\mathrm{f}}} \operatorname{RaPr} \theta \sin \varphi(2) \\
\frac{\partial V}{\partial \tau}+U \frac{\partial V}{\partial X}+V \frac{\partial V}{\partial Y}=-\frac{\partial P}{\partial Y}+\frac{\mu_{\mathrm{nf}}}{\rho_{\mathrm{nf}} \alpha_{\mathrm{f}}}\left(\frac{\partial^{2} V}{\partial X^{2}}+\frac{\partial^{2} V}{\partial Y^{2}}\right)+\frac{(\rho \beta)_{\mathrm{nf}}}{\rho_{\mathrm{nf}} \beta_{\mathrm{f}}} \operatorname{RaPr} \theta \cos \varphi(3) \\
U \frac{\partial \theta}{\partial X}+V \frac{\partial \theta}{\partial Y}=\frac{\alpha_{\mathrm{nf}}}{\alpha_{\mathrm{f}}}\left(\frac{\partial^{2} \theta}{\partial X^{2}}+\frac{\partial^{2} \theta}{\partial Y^{2}}\right)
\end{gathered}
$$

In the above equations (1-4), we introduce the following dimensionless variables:

$$
\begin{aligned}
& \tau=\frac{t \alpha_{\mathrm{f}}}{L^{2}}, X=\frac{x}{L}, Y=\frac{y}{L}, U=\frac{u L}{\alpha_{\mathrm{f}}}, V=\frac{v L}{\alpha_{\mathrm{f}}}, P=\frac{p L^{2}}{\rho_{\mathrm{f}} \alpha_{\mathrm{f}}^{2}} \\
& \theta=\frac{T-T_{\mathrm{C}}}{\bar{T}_{\mathrm{H}}-T_{\mathrm{C}}}, P r=\frac{\nu_{\mathrm{f}}}{\alpha_{\mathrm{f}}}, R a=\frac{g \beta_{\mathrm{f}}\left(T_{\text {avg }}-T_{\mathrm{C}}\right) L^{3}}{v_{\mathrm{f}} \alpha_{\mathrm{f}}}
\end{aligned}
$$

Where, thermal diffusivity of the nanofluids is

$$
\alpha_{\mathrm{nf}}=k_{\mathrm{nf}} /\left(\rho c_{\mathrm{p}}\right)_{\mathrm{nf}}
$$

The subscripts of $\mathrm{nf}, \mathrm{f}$ and $\mathrm{n}$ denote nanofuilds, water and nanoparticles respectively.

The viscosity of the nanofluids can be estimated with the existing relations for the two phase mixture. The effective dynamic viscosity of the nanofluids has been used as the relation for effective viscosity in this problem, as given by

$$
\mu_{\mathrm{nf}}=\mu_{\mathrm{f}} /(1-\phi)^{2.5}
$$

The heat capacitance and the thermal expansion coefficient of the nanofluids are expressed as:

$$
\begin{gathered}
\left(\rho c_{\mathrm{p}}\right)_{\mathrm{nf}}=(1-\phi)\left(\rho c_{\mathrm{p}}\right)_{\mathrm{f}}+\phi\left(\rho c_{\mathrm{p}}\right)_{\mathrm{s}} \\
(\rho \beta)_{\mathrm{nf}}=(1-\phi)(\rho \beta)_{\mathrm{f}}+\phi(\rho \beta)_{\mathrm{s}}
\end{gathered}
$$

Where, the effective density of the nanofluids is given as

$$
\rho_{\mathrm{nf}}=(1-\phi) \rho_{\mathrm{f}}+\phi \rho_{\mathrm{s}}
$$

The expression proposed by $\mathrm{Yu}$ and Choi [9] is used for calculating the effective thermal conductivity of nanofluids:

$$
\frac{k_{\mathrm{nf}}}{k_{\mathrm{f}}}=\frac{k_{\mathrm{s}}+2 k_{\mathrm{f}}-2(1+\eta)^{3}\left(k_{\mathrm{f}}-k_{\mathrm{s}}\right) \phi}{k_{\mathrm{s}}+2 k_{\mathrm{f}}+(1+\eta)^{3}\left(k_{\mathrm{f}}-k_{\mathrm{s}}\right) \phi}
$$

$\mathrm{Yu}$ and Choi [9] compared their model results for $\eta$ $=0.1$ with existing experimental results in literature and obtained a reasonably good agreement.

The dimensionless initial conditions and boundary conditions are as follows:

$$
\begin{aligned}
& \tau=0: \quad U=V=0, \quad \theta=1 \\
& X=0: \quad U=V=0, \quad \theta=1+A \sin (2 \pi F \tau) \\
& X=1: \quad U=V=0, \quad \theta=0 \\
& Y=0,1: \quad U=V=0, \quad \partial \theta / \partial Y=0
\end{aligned}
$$

Where, $F=1 / \tau_{\mathrm{p}}=L^{2} f / \alpha_{\mathrm{f}}$ is the dimensionless frequency of temperature alternation. $A=a /\left(T_{\mathrm{avg}}-T_{\mathrm{C}}\right)$ is the dimensionless amplitude of temperature alternation.

The average Nusselt number along the alternating temperature wall $(\mathrm{X}=0)$ and constant temperature wall $(\mathrm{X}=1)$ can be defined as:

$$
\begin{aligned}
& N u_{\mathrm{H}}=-\left.\int_{0}^{1} \frac{k_{\mathrm{nf}}}{k_{\mathrm{f}}} \frac{\partial \theta}{\partial X}\right|_{X=0} d Y \\
& N u_{\mathrm{C}}=-\left.\int_{0}^{1} \frac{k_{\mathrm{nf}}}{k_{\mathrm{f}}} \frac{\partial \theta}{\partial X}\right|_{X=1} d Y
\end{aligned}
$$

The time-averaged Nusselt number in one period at $\mathrm{X}=0,1$ can be given as follows:

$$
\begin{aligned}
& N u_{\mathrm{H}, \text { avg }}=-\left.\frac{1}{\tau_{\mathrm{p}}} \int_{0}^{\tau_{\mathrm{p}}} \int_{0}^{1} \frac{k_{\mathrm{nf}}}{k_{\mathrm{f}}} \frac{\partial \theta}{\partial X}\right|_{X=0} d Y d \tau \\
& N u_{\mathrm{C}, \mathrm{avg}}=-\left.\frac{1}{\tau_{\mathrm{p}}} \int_{0}^{\tau_{\mathrm{p}}} \int_{0}^{1} \frac{k_{\mathrm{nf}}}{k_{\mathrm{f}}} \frac{\partial \theta}{\partial X}\right|_{X=1} d Y d \tau
\end{aligned}
$$

The dimensionless governing Eqs. (1-4) are solved with finite volume approach using SIMPLEC algorithm. The convective terms are discredited by using the QUICK scheme, and a second-order central difference scheme is 
used for the diffusion terms. The corresponding algebraic equations are solved by the TDMA [10].

The convergence of computations is declared at each time instant when the following criterion is satisfied:

$$
\Sigma_{i, j}\left|\left(\varepsilon_{i, j}{ }^{n+1}-\varepsilon_{i, j}{ }^{n}\right) / \varepsilon_{i, j}{ }^{n+1}\right| \leq 10^{-5}
$$

Where, $\varepsilon$ stands for $U, V$ and $\theta . n$ is internal iteration number.

Accuracy tests are performed using three sets of grids: $42 \times 42,52 \times 52$, and $62 \times 62$ and three sets of time step $10^{-3}$, $10^{-4}$ and $10^{-5}$ at $R a=10^{5}, A=0.8, \phi=0.1$ and $\tau_{\mathrm{p}}=0.1$. Table II shows the time-averaged Nusselt numbers under the different grids for $\Delta \tau=10^{-5}$. It is clearly seen that the grid of $62 \times 62$ can eliminate the influences of grid density on the simulated results. Table III shows the time-averaged Nusselt numbers under the different step times for $62 \times 62$. It is clearly seen that the step time of $10^{-4}$ can eliminate the influences of the iterative step on the simulated results. Therefore, the grid of $62 \times 62$ and the step time of $10^{-4}$ are still used in the following research.

In addition, the present code is further validated against the study of natural convection of nanofluids. It can be seen from Table IV that the present results agree very well with those obtained by the Kahveci [11]. These comprehensive verification efforts demonstrate great robustness and accuracy of the present numerical method.

TABLE II. ThE EVALUATION ABOUT THE GRID

\begin{tabular}{|c|c|c|c|}
\hline \multirow{2}{*}{$\boldsymbol{\varphi}$} & \multicolumn{3}{|c|}{$\boldsymbol{N} \boldsymbol{u}_{\mathbf{H}, \mathbf{a v g}}$} \\
\cline { 2 - 4 } & $\mathbf{4 1 \times 4 1}$ & $\mathbf{6 1 \times 6 1}$ & $\mathbf{8 1 \times \boldsymbol { 8 1 }}$ \\
\hline$-60^{\circ}$ & 2.183 & 2.011 & 2.009 \\
\hline$-30^{\circ}$ & 6.298 & 6.119 & 6.119 \\
\hline $0^{\circ}$ & 11.634 & 11.687 & 11.686 \\
\hline $30^{\circ}$ & 12.681 & 12.546 & 12.540 \\
\hline $60^{\circ}$ & 10.512 & 10.411 & 11.402 \\
\hline
\end{tabular}

TABLE III. THE EVALUATION ABOUT ITERATIVE STEP

\begin{tabular}{|c|c|c|c|}
\hline \multirow{2}{*}{$\boldsymbol{\rho}$} & \multicolumn{3}{|c|}{$\boldsymbol{N} \boldsymbol{u}_{\mathrm{H}, \mathrm{avg}}$} \\
\cline { 2 - 4 } & $\Delta \boldsymbol{\tau}=\mathbf{1 0}^{-3}$ & $\Delta \boldsymbol{\tau}=\mathbf{1 0}^{-4}$ & $\Delta \boldsymbol{\tau}=\mathbf{1 0}^{-5}$ \\
\hline$-60^{\circ}$ & 1.803 & 2.010 & 2.011 \\
\hline$-30^{\circ}$ & 5.909 & 6.116 & 6.119 \\
\hline $0^{\circ}$ & 114612 & 11.683 & 11.687 \\
\hline $30^{\circ}$ & 12.343 & 12.546 & 12.546 \\
\hline $60^{\circ}$ & 10.112 & 10.410 & 10.411 \\
\hline
\end{tabular}

TABLE IV. CODE VALIDATION FOR CU-WATER NANOFLUID AGAINST KAHVECI

\begin{tabular}{|c|c|c|c|c|}
\hline \multirow{2}{*}{$\boldsymbol{R} \boldsymbol{a}$} & \multirow{2}{\boldsymbol{p}}{} & \multicolumn{3}{|c|}{$\boldsymbol{N} \boldsymbol{u}_{\mathrm{H}, \mathrm{avg}}$} \\
\cline { 3 - 5 } & 0 & Present & Kahveci[11] & Error(\%) \\
\hline $10^{5}$ & 5.788 & 5.662 & $2.231 \%$ \\
\hline $10^{5}$ & 30 & 6.183 & 6.063 & $1.983 \%$ \\
\hline $10^{5}$ & 60 & 5.725 & 5.723 & $0.039 \%$ \\
\hline $10^{6}$ & 0 & 11.466 & 11.227 & $2.134 \%$ \\
\hline $10^{6}$ & 30 & 11.726 & 11.600 & $1.090 \%$ \\
\hline $10^{6}$ & 60 & 10.372 & 10.269 & $1.070 \%$ \\
\hline
\end{tabular}

\section{RESULTS AND DISCUSSIONS}

Firstly, to mainly study the effects of the $R a$ number and the volume fraction of nanaparticles on natural convection under the different inclined angles, the dimensionless amplitude and frequency are kept constant:
$\operatorname{Pr}=6.2, A=0.8$ and $F=10$ in this research and after ten alternating periods, the alternating solution independent of initial state can be obtained and the tenth period is main analysis object

\section{A. Influence of the inclined angle}

Fig .2 shows the transient responses of the average Nusselt number with time at the alternating temperature wall, $N u_{\mathrm{H}}$, and that at constant temperature wall, $N u_{\mathrm{C}}$ for different inclined angles at $R a=10^{6}$ and $\phi=0.1$. It can be seen that the varying waveforms of $N u_{\mathrm{H}}$ are approximately the same with the temperature sinusoidal wave. Although temperature on the left sidewall is always higher than that on the right sidewall, there is the negative value of $N u_{\mathrm{H}}$, which shows the heat removes out of the cavity at the certain times. Moreover, $N u_{\mathrm{C}}$ has also the sinusoidal tendency, but its amplitude is obviously lower than that of $N u_{\mathrm{H}}$ especially when $\varphi$ is less than 0 . As shown in the figure, the full line is still above the dash line, which shows the positive inclined angle is more conducive to improving the convective heat transfer strength than the negative angle. From the $N u_{\mathrm{C}}$, it is easily seen $N u_{\mathrm{C} \text {,avg }}$ gradually decreases with the increase of $\varphi$ from $-60^{\circ}$ to $30^{\circ}$ or from $30^{\circ}$ to $60^{\circ}$. From the $N u_{\mathrm{H}}$, it is difficult to analyze this rule. However, through the further data processing, it is found that $N u_{\mathrm{H}, \mathrm{avg}}=N u_{\mathrm{C}, \mathrm{avg}}=12.5$ at $\varphi=30^{\circ}$, $N u_{\mathrm{H}, \mathrm{avg}}=N u_{\mathrm{C}, \mathrm{avg}}=11.6$ at $\varphi=45^{\circ}$ and $N u_{\mathrm{H}, \mathrm{avg}}=N u_{\mathrm{C}, \mathrm{avg}}=10.4$ at $\varphi=60^{\circ}$, which indicate the heat transfer gradually decreases with the increase of $\varphi$ from $30^{\circ}$ to $60^{\circ}$. And $N u_{\mathrm{H}, \mathrm{avg}}=N u_{\mathrm{C}, \mathrm{avg}}=6.1$ at $\varphi=-30^{\circ}, N u_{\mathrm{H}, \mathrm{avg}}=N u_{\mathrm{C}, \mathrm{avg}}=3.3$ at $\varphi$ $=-45^{\circ}$ and $N u_{\mathrm{H}, \mathrm{avg}}=N u_{\mathrm{C}, \mathrm{avg}}=2.0$ at $\varphi=-60^{\circ}$. It shows both $N u_{\mathrm{H}}$ and $N u_{\mathrm{C}}$ have the same rules.
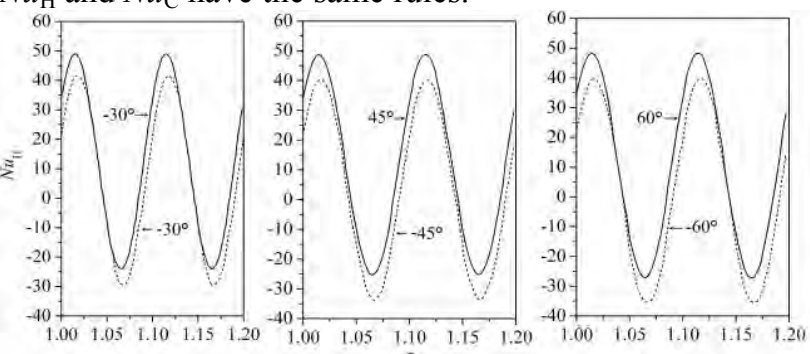

(a) Variation of $N u_{\mathrm{H}}$ with $\tau$

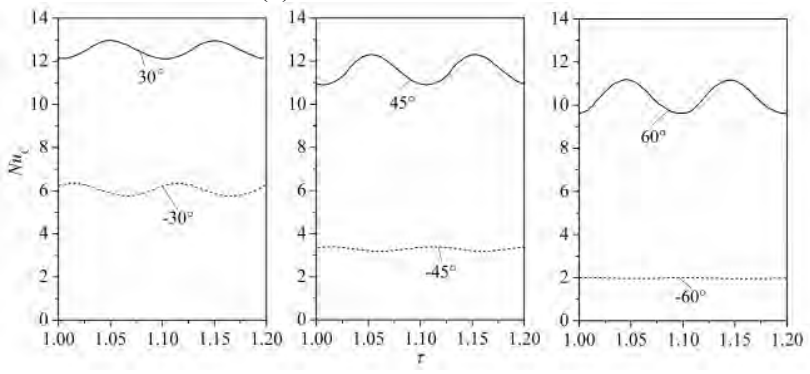

(b) Variation of $N u_{\mathrm{C}}$ with $\tau$

Figure 2. Transient responses $N u_{\mathrm{H}}$ and $N u_{\mathrm{C}}$ for different $\varphi$ at $R a=10^{6}$ and $\phi=0.1$

\section{B. Influence of Nanoparticle Volume Fraction}

Fig .3 shows the transient responses of the average Nusselt number with time at the alternating temperature wall, $N u_{\mathrm{H}}$, and that at constant temperature wall, $N u_{\mathrm{C}}$ for different values of $\phi$ with $R a=10^{6}$ and $\varphi=0^{\circ}$. We can 
observe that both $N u_{\mathrm{H}}$ and $N u_{\mathrm{C}}$ curves vary in time similar to a sine curve, and there is phase difference in $N u_{\mathrm{C}}$ and $N u_{\mathrm{H}}$ due to thermal inertia of nanofluids and time spent of nanofluids flowing from the hot wall to the cool wall in the natural convection. At the same time, this flow also causes thermal dissipation, so the amplitude of $N u_{\mathrm{C}}$ is obviously smaller than that of $N u_{\mathrm{H}}$. The maximum positive amplitudes for $N u_{\mathrm{H}}$ and $N u_{\mathrm{C}}$ curves increase and the minimum negative amplitudes are basically kept at constant values with the increase of $\phi$. This indicates that the time-averaged Nusselt number increases with the increase of $\phi$, so the significant heat transfer can be enhanced by using nanoparticles in the base fluid. The $N u_{\mathrm{H}}$ ha the partial negative number showing that heat is removed out from the cavity through the hot wall during the part time of this period.

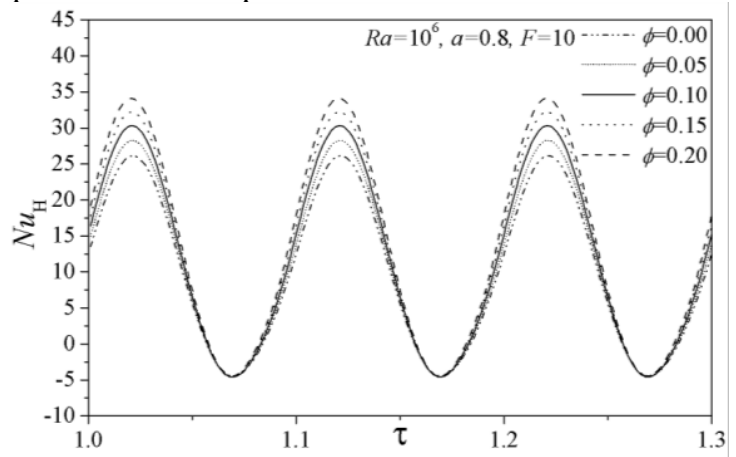

(a) Variation of $N u_{\mathrm{H}}$ with $\tau$

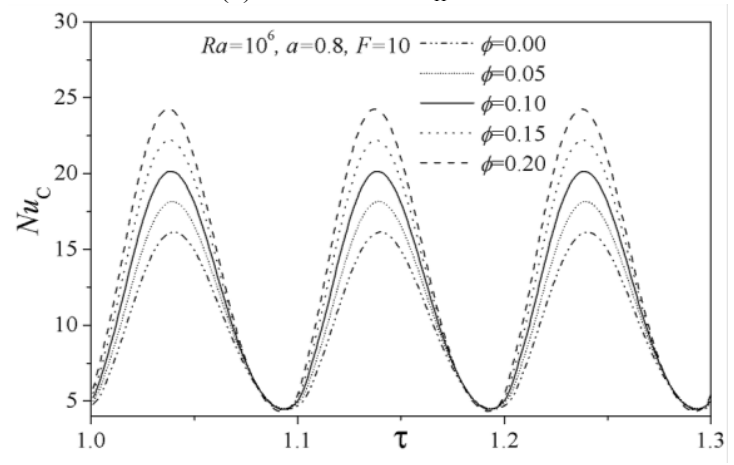

(b) Variation of $N u_{\mathrm{C}}$ with $\tau$

Figure 3. Transient responses $N u_{\mathrm{H}}$ and $N u_{\mathrm{C}}$ for different $\phi$ at $R a=10^{6}$ and $\varphi=0^{\circ}$

\section{Influence of the Ra Number}

Fig. 4 shows the transient responses of the average Nusselt number with time at the alternating temperature wall, $N u_{\mathrm{H}}$, and that at constant temperature wall, $N u_{\mathrm{C}}$ for the different $R a$ at $\phi=0.1$ and $\varphi=0^{\circ}$. It can be clearly seen that for the $N u_{\mathrm{H}}$, the negative and positive amplitudes have increased with the increase of the $R a$ number, but the increase of positive amplitude is much larger than that of negative amplitude. For the $N u_{\mathrm{C}}$, the change curve of the higher $R a$ number is always above that of the lower $R a$ number. Therefore, the $N u_{\mathrm{H}}$ and $N u_{\mathrm{C}}$ increases with the increasing of the $R a$ number, which shows the increase of the $R a$ number can strengthen the convective heat transfer.

\section{Performance of the time-averaged Nusselt number}

Fig .5 shows the variation of the time-averaged Nusselt number $N u_{\mathrm{H}, \text { avg }}$ with $\phi$ for different $R a$ at $\varphi=0^{\circ}$. To the problem of our study, the value of $N u_{\mathrm{H} \text {,avg }}$ is the same as $N u_{\text {C,avg, }}$ after eliminating the influence of the initial state. Therefore, $N u_{\mathrm{H} \text {,avg }}$ is used as the main analysis object. It can be seen that the time-averaged Nusselt number increases linearly with $\phi$ for the same $R a$. The higher the $R a$ number, the larger the straight slope, which proves that using copper nanoparticles in water can get more obvious strength in the higher $R a$. It is found that the percentage increase in the time-averaged Nusselt number is $37.61 \%$, when the solid volume fraction is increased from $\phi=0$ to $\phi=0.2$ at $R a=10^{6}$ and $\varphi=0^{\circ}$.

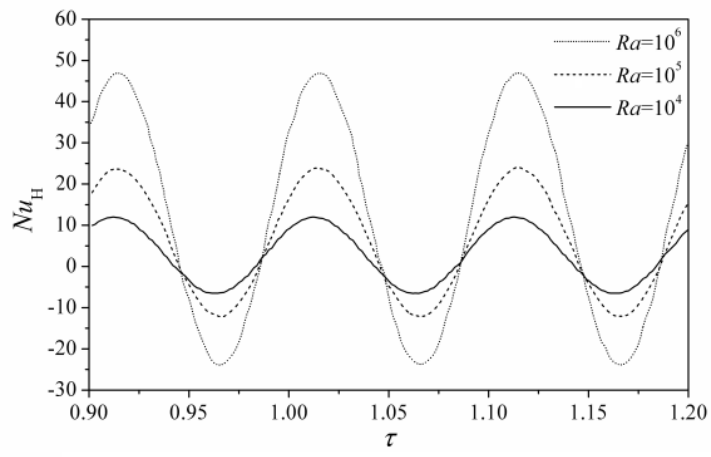

(a) Variation of $N u_{\mathrm{H}}$ with $\tau$

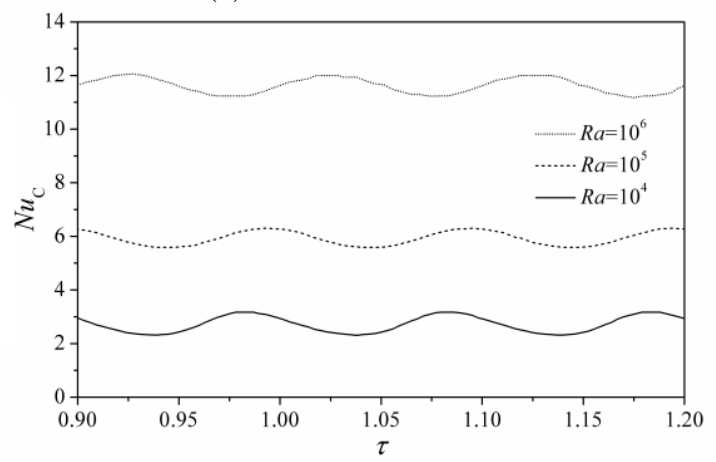

(b) Variation of $N u_{\mathrm{C}}$ with $\tau$

Figure 4. Transient responses $N u_{\mathrm{H}}$ and $N u_{\mathrm{C}}$ for different $R a$ at $\phi=0.1$ and $\varphi=0^{\circ}$

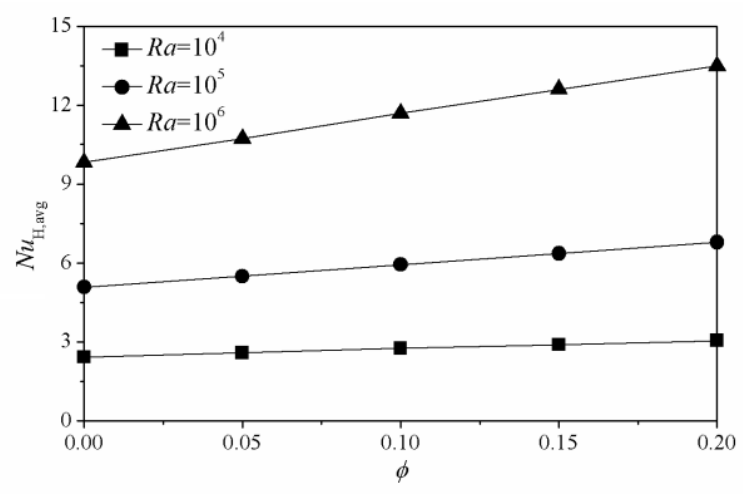

Figure 5. Variation of $N u_{\mathrm{H}, \text { avg }}$ with $\phi$ for different $R a$ at $\varphi=0^{\circ}$

Fig .6 shows the variation of the time-averaged

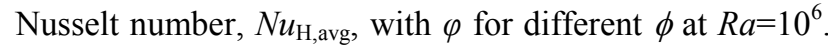
It can be clearly seen that the $N u_{\mathrm{H} \text {,avg }}$ first increases and then decreases with the increase of $\varphi$ from $-75^{\circ}$ to $75^{\circ}$, and there is a maximum $N u_{\mathrm{H} \text {,avg }}$ for the different $\phi$ at 
$\varphi=15^{\circ}$. Moreover, the $N u_{\mathrm{H} \text {,avg }}$ with $\varphi$ more than $0^{\circ}$ is higher than that with $\varphi$ less than $0^{\circ}$, and this conclusion shows that it is conducive to convective heat transfer enhancement, when the wall with high temperature is below the cavity. Comparing the different $\phi$, it is easily found that the convective heat transfer become stronger with the increase of $\phi$, which shows the significant heat transfer can be enhanced by using nanoparticles in the base fluid.

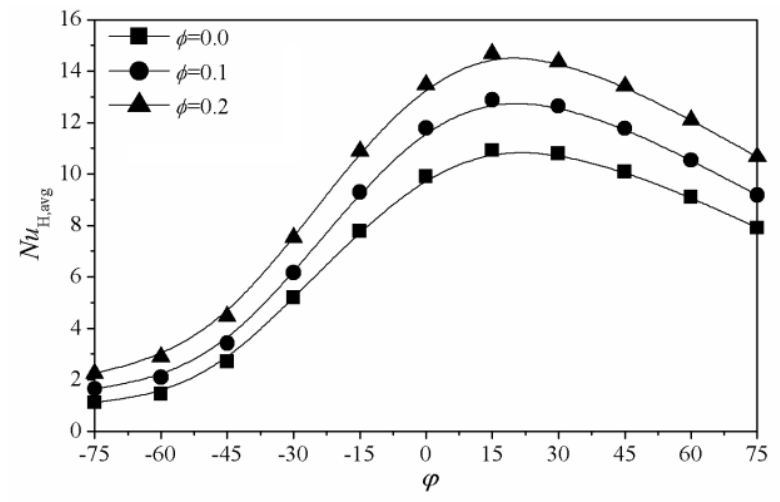

Figure 6. Variation of $N u_{\mathrm{H}, \text { avg }}$ with $\varphi$ for different $\phi$ at $R a=10^{6}$

Fig .7 shows the variation of the time-averaged

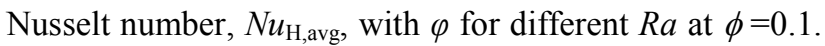
It can be clearly seen that the $N u_{\mathrm{H} \text {,avg }}$ first increases and then decreases with the increase of $\varphi$ from $-75^{\circ}$ to $75^{\circ}$. And there is a maximum $N u_{\mathrm{H}, \text { avg }}$ at $\varphi=15^{\circ}$ for $R a=10^{6}$, at $\varphi=30^{\circ}$ for $R a=10^{4}$ and $\varphi=45^{\circ}$ for $R a=10^{3}$. But there is the obvious maximum for $R a=10^{6}$, while there is not obvious for $R a=10^{5}$ and $R a=10^{4}$, and even the $N u_{\mathrm{H} \text {,avg }}$ is almost horizontal for $R a=10^{4}$. This is mainly because heat transfers in the cavity through the natural convection and the inclined angle has influence on the fluid flow in the cavity when the $R a$ number is higher, while heat transfers in the cavity through the heat conduction and the inclined angle has little influence on heat transfer when the $R a$ number is lower. Comparing the different $R a$, it is easily found that the convective heat transfer become stronger with the increase of $R a$, which shows the significant heat transfer can be enhanced by increase of $R a$. It is mainly because when the $R a$ number is higher, heat transfers by the natural convection, which has more effective than heat conduction.

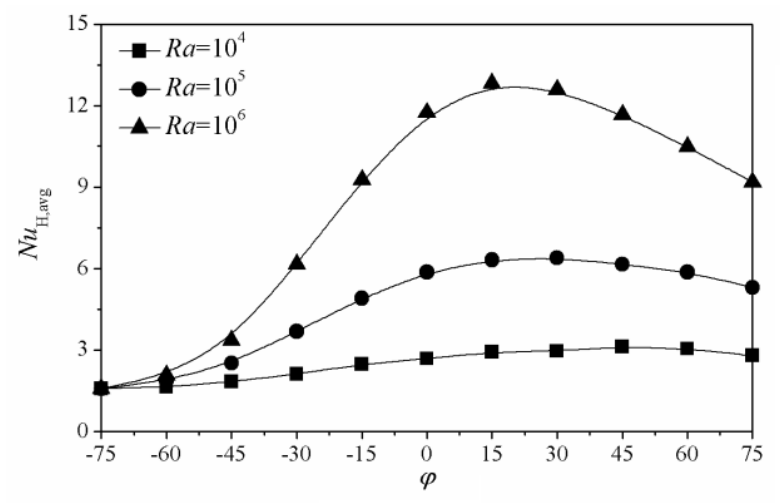

Figure 7. Variation of $N u_{\mathrm{H}, \mathrm{avg}}$ with $\varphi$ for different $R a$ at $\phi=0.1$

\section{CONCLUSION}

It is numerically studied that the effect of periodic alternating wall temperature on the natural convection heat transfer enhancement in an inclined square cavity filled with $\mathrm{Cu}$-water nanofluids. The results lead to the following conclusions:

(1) The positive inclined angle is more conducive to heat transfer enhancement than the negative inclined angle, especially for the higher $R a$ number. The $N u_{\mathrm{H} \text {,avg first }}$ increases and then decreases with the increase of $\varphi$ from $75^{\circ}$ to $75^{\circ}$ and there is the maximum $N u_{\mathrm{H} \text {,avg }}$ at $\varphi=15^{\circ}$ for $R a=10^{6}$, at $\varphi=30^{\circ}$ for $R a=10^{4}$ and $\varphi=45^{\circ}$ for $R a=10^{3}$.

(2) The higher $R a$ number is more conducive to heat transfer, because the higher $R a$ number can improve the natural convection strength. And the higher the $R a$ number, the more obvious the improvement of heat transfer strength due to the nanaparticles.

(3) Under the alternating temperature conditions, using copper nanoparticles in pure water can strengthen natural convection heat transfer. The higher solid volume fraction, the greater strength of heat transfer. And the percentage increase in the time-averaged Nusselt number is $37.61 \%$, when the solid volume fraction is increased from $\phi=0$ to $\phi$ $=0.2$ at $R a=10^{6}$.

\section{ACKNOWLEDGMENT}

The authors gratefully acknowledge the financial support from the National Nature Science Foundation of China under Grant No.51178282, No.51308361 and No 51478280 .

\section{REFERENCES}

[1] S.M.S. Murshed, C.A.N.D. Castro, M.J.V. Lourenco, M.L.M Lopes and F.J.V. Santos, "A review of boiling and convective heat transfer with nanofluids", Renewable and Sustainable Energy Reviews, vol. 15, 2011, pp. 2342-2354

[2] W.H. Yu, M.D. France, E.V. Timofeeva, D. Singh, and J.L. Routbort, "Comparative review of turbulent heat transfer of nanofluids", International Journal of Heat and Mass Transfer, vol. 55, 2012, pp. 5380-5396.

[3] S. Kakac, and A.Pramuanjaroenkij, "Review of convective heat transfer enhancement with nanofluids", International Journal of Heat and Mass Transfer, vol. 52, 2009, pp. 3187-3196.

[4] R. Saidura, K.Y. Leong, and H.A. Mohammadc, "A review on applications and challenges of nanofluids", Renewable and Sustainable Energy Reviews, vol. 15, 2011, pp. 1646-1668.

[5] G. Huminic, and A. Huminic, "Application of nanofluids in heat exchangers: A review", Renewable and Sustainable Energy Reviews, vol. 16, 2012, pp. 5625-5638.

[6] Y.M. Xuan and Q. Li, "Energy transfer theory and application of nanofuilds", Beijing: Science press,2010, pp245-247

[7] G. Wang, Q.W. Wang, M. Zeng and H.Ozoe, "Natural convection heat transfer in an inclined porous cavity under time-periodic boundary conditions with positive/negative inclined angles", Journal of Porous Media, vol. 11, 2008, pp. 541-555

[8] B. Ghasemi and S.M. Aminossadati, "Periodic natural convection in a nanofluids-filled enclosure with oscillating heat flux", International Journal of Thermal Sciences, vol.49, 2010, pp.1-9.

[9] W. Yu and S.U.S. Choi, "The role of interfacial layers in the enhanced thermal conductivity of nanofluids: a renovated Maxwell model", Journal of Nanoparticles Research, vol. 5, pp. 167-171, 2003

[10] W.Q. Tao, "numerical heat transfer (The second edition)", Xi'an: Xi'an Jiaotong University Press, 2006, PP356-369. K. Kahveci, "Buoyancy driven heat transfer of nanofluids in a tilted enclosure", ASME Journal of Heat Transfer, vol. 132, 062501, 2010. 